\title{
BMJ Open Sex-based differences in and risk factors for metabolic syndrome in adults aged 40 years and above in Northeast China: Results from the cross-sectional China national stroke screening survey
}

\author{
Feng-E Li, ${ }^{1,2}$ Fu-Liang Zhang, ${ }^{1}$ Peng Zhang, ${ }^{3}$ Dong Liu, ${ }^{2}$ Hao-Yuan Liu, ${ }^{1}$ \\ Zhen-Ni Guo, ${ }^{3}$ Yi Yang (D) 1,3
}

To cite: Li F-E, Zhang F-L, Zhang P, et al. Sex-based differences in and risk factors for metabolic syndrome in adults aged 40 years and above in Northeast China: Results from the crosssectional China national stroke screening survey. BMJ Open 2021;11:e038671. doi:10.1136/ bmjopen-2020-038671

- Prepublication history and additional material for this paper is available online. To view these files, please visit the journal online (http://dx.doi.org/10. 1136/bmjopen-2020-038671).

Received 21 March 2020 Revised 23 February 2021 Accepted 02 March 2021

Check for updates

(c) Author(s) (or their employer(s)) 2021. Re-use permitted under CC BY-NC. No commercial re-use. See rights and permissions. Published by BMJ.

For numbered affiliations see end of article.

Correspondence to

Professor Yi Yang; doctoryangyi@163.com and

Dr Zhen-Ni Guo;

zhen1ni2@163.com

\section{ABSTRACT}

Objectives Low levels of income and education are risk factors for metabolic syndrome in the population of Northeast China, which has a high incidence of metabolic syndrome and cardiovascular diseases. This study aimed to determine sex-based differences associated with the prevalence of and risk factors for metabolic syndrome among people older than 40 years in Northeast China; this has not been previously investigated.

Design This study analysed a portion of the large sample data of the national cross-sectional screening of China from 2016. Metabolic syndrome was defined as the presence of any three of the following five risk factors: abnormal waist circumference; high levels of triglycerides, high-density lipoprotein cholesterol or fasting plasma glucose; and elevated blood pressure. Multiple regression analysis was used to investigate sex-based differences in the prevalence of, and risk factors for metabolic syndrome. Setting The study was conducted in Dehui City, Jilin Province, China.

Participants A total of 4052 participants with complete questionnaire information and laboratory examination results were included.

Results The prevalence of metabolic syndrome was $50.1 \%$ overall ( $38.4 \%$ in men and $57.9 \%$ in women; $\mathrm{p}<0.001)$. High body mass index and hip circumference were associated with metabolic syndrome in both sexes. In addition, physical inactivity (OR and 95\% $\mathrm{Cl} 1.44$ (1.06 to $1.97) ; p=0.022)$ in men and advanced age (OR and $95 \% \mathrm{Cl}$ 1.54 (1.15 to 2.04); $p=0.003$ ) in women were factors associated with metabolic syndrome. Women with junior high school education or above and living in rural areas were less likely to have metabolic syndrome. For men, education and rural or urban living had no association with metabolic syndrome.

Conclusions The risk factors for metabolic syndrome have similarities and differences in different sexes; thus, the prevention and treatment of metabolic syndrome should be based on these sex differences.

\section{INTRODUCTION}

Metabolic syndrome (MS) is associated with a cluster of cardio-metabolic risk factors and
Strengths and limitations of this study

This cross-sectional study included a large, representative sample of the Chinese population.

- We used a uniform, precoded questionnaire designed by the national stroke screening survey of China.

- Some results were partially based on self-reported data collected by investigators, which inevitably increased the risk of recall bias.

- Our survey excluded participants who were sick or too weak to complete the interview.

- As a major limitation of all epidemiological investigations, conclusions based on cross-sectional studies cannot be used for causal inferences.

has become one of the major public health threats in China. Higher prevalence of MS greatly increases the burden of morbidity and mortality due to cardiovascular diseases worldwide. ${ }^{1-3}$ This burden has increased every year, although it is difficult to differentiate it from unhealthy habits of daily living. ${ }^{4}$ There is a significant difference in the prevalence of, and risk factors for MS between men and women. ${ }^{5}$ To control and reduce the risk of MS and cardiovascular diseases more effectively, it is necessary to identify high-risk populations and understand the sex-specific, modifiable lifestyle determinants of MS. Northeast China, with its low-income level, has a high incidence of MS and cardiovascular diseases. Specifically, it has the highest incidence and mortality rate of stroke (365 and 159/100 000 person years) in China. ${ }^{6}$ Thus, this study aimed to analyse the sexspecific differences in the prevalence of MS and its related risk factors in a population from Northeast China. 


\section{POPULATION AND METHODS}

\section{Data source and study participants}

This population-based cross-sectional study was a part of the Stroke Screening and Prevention Program of the National Health and Family Planning Commission of China (CNSSS). It assessed a population of residents aged 40 years or older, from January to March 2016. The CNSSS is a national epidemiological survey of cerebrovascular diseases conducted to obtain timely and reliable information on the morbidity, prevalence and mortality of stroke in Chinese people over the age of $40 .^{7}$ The sampling method employed in this study has been described in detail in other articles. ${ }^{8}$ The sample size (N) required for this survey was calculated on a $2.37 \%$ stroke prevalence (p) among adults 40 years and older in China, ${ }^{8}$ using the formula:

$\mathrm{N}=\left(\mathrm{Z}_{\alpha}^{2} \mathrm{pq}\right) / \mathrm{d}^{2}\left(\right.$ where $\mathrm{Z}_{\alpha}=1.96, \alpha=0.05, \mathrm{q}=1-\mathrm{p}$, and $\mathrm{d}=0.2 \mathrm{p})$

A multistage stratified, random cluster sampling method was applied to obtain the sample population. In the first stage, 30 villages and 10 towns were randomly selected from a total of 308 villages (rural) and 14 towns (urban) in Dehui City, using the probability proportional to size (PPS) sampling method. In the second stage, five groups of villages or communities were randomly sampled from both the rural and urban strata using PPS sampling. In the third stage, one participant aged $\geq 40$ years was randomly selected from each household of the selected groups of villages or communities. Respondents who were unwilling to participate in the survey or who were judged to be very frail were excluded. We selected permanent residents aged $\geq 40$ years for inclusion in the study (a calculated total of 4445 participants with an additional $10 \%$ loss rate); ultimately, 4100 participants completed the face-to-face survey, with a good response rate of $92.2 \%$. In this substudy of the CNSSS, we used data from participants who completed the study. After excluding 48 participants with incomplete questionnaire information or laboratory examinations, a total of 4052 participants were included in this analysis. The flowchart of the study selection process is shown in figure 1 .

\section{Patient and public involvement}

Patients and the public were not involved in the development of the research questionnaire, its outcome measures, study design, recruitment methods or the conduct of this study. There is no plan to disseminate the research findings to the participants.

\section{Data collection and measurement}

All participants completed a questionnaire that included an assessment of general sociodemographic and healthrelated information. Physical examinations included assessments of height, weight, neck, waist, and hip circumferences, and blood pressure. Height and weight were measured according to the standard methods; the subjects removed their shoes and hats and wore light clothes. The measurement accuracy was within $0.1 \mathrm{~cm}$ and
$0.1 \mathrm{~kg}$ for the height and weight, respectively. Blood pressure was measured by physicians using an OMRON automatic sphygmomanometer (OMRON HEM-7200, Kyoto, Japan), on the right arm, after placing it parallel to the heart. The subjects were made to rest for $20 \mathrm{~min}$ before the blood pressure was measured twice, and mean value was recorded. Blood samples were collected on an empty stomach following overnight fasting (at least 8 hours) to assess fasting plasma glucose (FPG), triglyceride (TG), total cholesterol (TC), low-density lipoprotein cholesterol (LDL-C) and high-density lipoprotein cholesterol (HDL-C) concentrations. The samples were sent to the clinical laboratory of Changchun Kingmed Centre (Chang Chun, Jilin, China) for testing.

\section{Screening protocol and assessment criteria}

The definition of MS used in this study was published by the International Diabetes Federation and the American Heart Association/National Heart, Lung, and Blood Institute. ${ }^{9}$ The presence of any three of the following five risk factors constituted a diagnosis of MS: (1) waist circumference: $\geq 90 \mathrm{~cm}$ for men, and $\geq 80 \mathrm{~cm}$ for women; (2) TG concentration: $\geq 1.70 \mathrm{mmol} / \mathrm{L}$ (drug treatment for elevated TG levels was an alternative indicator); (3) HDL-C concentration: $<1.0 \mathrm{mmol} / \mathrm{L}$ for men, and $<1.3 \mathrm{mmol} / \mathrm{L}$ for women (drug treatment for reduced HDL-C levels was an alternative indicator); (4) blood pressure: systolic blood pressure $\geq 130 \mathrm{~mm} \mathrm{Hg}$ and/or diastolic blood pressure $\geq 85 \mathrm{~mm} \mathrm{Hg}$ (antihypertensive drug treatment in a patient with a history of hypertension was an alternative indicator); and (5) FPG concentration: $\geq 5.6 \mathrm{mmol} / \mathrm{L}$ (drug treatment for elevated glucose levels was an alternative indicator).

In addition to stratification by sex, participants were also stratified by age into a middle-aged group (40-64 years old) and an elderly group ( $\geq 65$ years old). The evaluation criteria for other factors, including body mass index (BMI), level of physical inactivity, smoking status, and alcohol consumption are shown in online supplemental table S1.

\section{Statistical analysis}

The normality of the data was tested using the KolmogorovSmirnov test. Non-normally distributed continuous variables are presented as medians (IQRs). Categorical data are presented as numbers and proportions. Significant variables (those with $\mathrm{p}<0.05$ ) identified in the single variable analysis were selected for the multivariable analyses. Multiple logistic regression analysis was used to explore the independent risk factors of MS in the two sexes, and the ORs and 95\% CIs were calculated. All statistical analyses were performed using IBM Statistical Package for the Social Sciences (SPSS) V.23.0 (SPSS, Inc., New York, NY, USA). $\mathrm{P}<0.05$ was considered statistically significant. 


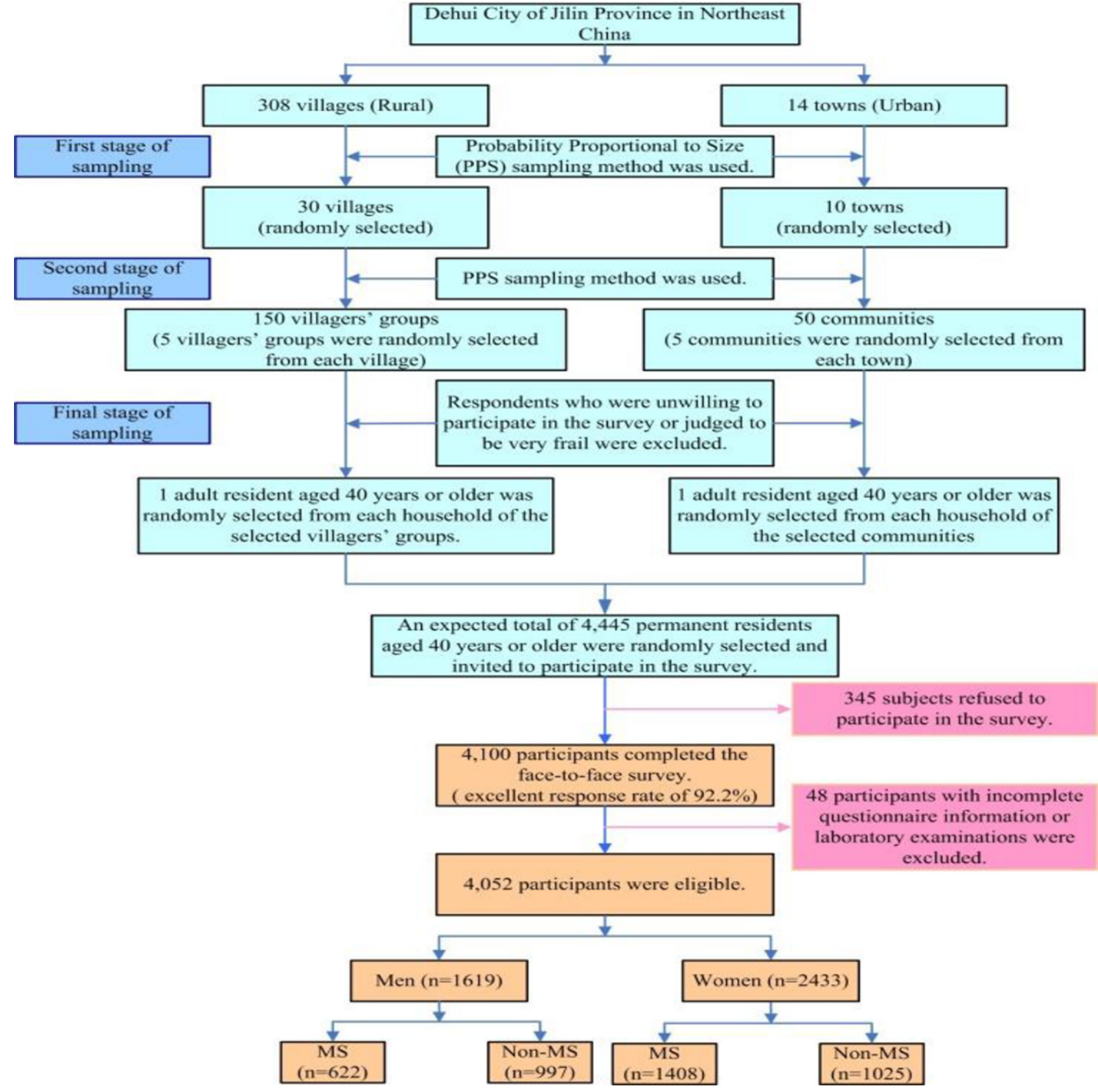

Figure 1 Sampling process in the study. MS, metabolic syndrome.

\section{RESULTS}

Among the 4100 participants who completed the face-toface survey, 4052 were included in the analysis. A total of 2030 individuals met the criteria for MS, and the prevalence was $50.1 \%$ overall $(38.4 \%$ in men and $57.9 \%$ in women; $\mathrm{p}<0.001)$. Of all the 4052 participants, 1619 were men $(40.0 \%)$ and 2433 were women $(60.0 \%)$, with a median age of 53 years (IQR: $47-62$ ). Overall, $76.7 \%$ of the participants were educated up to either primary and below or junior middle-school level.

\section{Demographic characteristics of all participants with MS}

Table 1 shows that compared with that in men (38.4\%), the prevalence of MS in women $(57.9 \%)$ was significantly higher. Among the 2030 individuals with MS, the median age was 56 years (IQR: 49-63), and for both men and women, more than $80 \%$ of the participants with MS were in the group of 40-64 years. The rate of abnormal waist circumference in women $(91.6 \%)$ was higher than that in men $(85.4 \%)$. The median neck and hip circumferences in men were higher than those in women. Compared with men, women had a higher proportion of the following associated risk factors: a lower level of educational attainment, living in a rural area, an abnormal HDL-C concentration, and higher concentrations of TC and LDL-C. However, a higher proportion of men than women had hypertension, abnormal levels of TGs and fasting blood glucose, abnormal BMI, resided in urban areas, had a smoke habit, and cousumed alcohol.

\section{Univariable analysis of factors associated with MS stratified by sex}

Table 2 shows the results of univariable logistic regression for factors associated with MS in men and women. The prevalence of MS was higher in the elderly (figure 2: men:40.2\%; women: $71.7 \%$ ), especially in older women (Table 2: OR $(95 \% \mathrm{CI})=2.04(1.61$ to 2.59$) ; \mathrm{p}<0.001)$. For women, age, BMI, hip and neck circumference, smoking, higher alcohol consumption, geographical region, and level of educational attainment were associated with 
Table 1 Sex differences in demographic characteristics and risk factors among participants with metabolic syndrome.

Total

Participants, n (\%)

Cases, $\mathrm{n}(\%)$

Age, years, median (IQR)

Age group, $n(\%)$

$40-64$ years
$\geq 65$ years

Waist circumference, $\mathrm{n}(\%)$

Neck circumference, median (IQR)

Hip circumference, $\mathrm{n}(\%)$

$\mathrm{TCHO}, \mathrm{mmol} / \mathrm{L}$, median (IQR)

LDL-C, mmol/L, median (IQR)

HDL-C, n (\%)

TG, n (\%)

FBG, $n(\%)$

Hypertension, $\mathrm{n}(\%)$

Education, $\mathrm{n}(\%)$

$\leq$ Primary schoo

Junior middle school

Senior middle school

College and above

Region, n (\%)

\begin{tabular}{|c|c|c|c|}
\hline Urban & $1023(50.4)$ & $357(57.4)$ & $666(47.3)$ \\
\hline Rural & $1007(49.6)$ & 265 (42.6) & $742(52.7)$ \\
\hline \multicolumn{4}{|l|}{ Smoke, n (\%) } \\
\hline No & $1021(50.3)$ & $223(35.9)$ & $798(56.7)$ \\
\hline Yes & $1009(49.7)$ & $399(64.1)$ & $610(43.3)$ \\
\hline \multicolumn{4}{|l|}{ Physical inactivity, n (\%) } \\
\hline No & $1522(75.0)$ & $469(75.4)$ & $1053(74.8)$ \\
\hline Yes & $508(25.0)$ & $153(24.6)$ & $355(25.2)$ \\
\hline \multicolumn{4}{|l|}{ Alcohol consumption, $\mathrm{n}(\%)$} \\
\hline Never & $1591(78.4)$ & $251(40.4)$ & $1340(95.2)$ \\
\hline Light/moderate & $245(12.1)$ & $182(29.3)$ & $63(4.5)$ \\
\hline Heavier & $194(9.6)$ & $189(30.4)$ & $5(0.4)$ \\
\hline \multicolumn{4}{|l|}{ Fruit consumption, $\mathrm{n}(\%)$} \\
\hline$\geq 5$ days per week & $1782(87.8)$ & $546(87.8)$ & $1236(87.8)$ \\
\hline 3-4 days per week & $189(9.3)$ & $61(9.8)$ & $128(9.1)$ \\
\hline$\leq 2$ days per week & 59 (2.9) & $15(2.4)$ & $44(3.1)$ \\
\hline \multicolumn{4}{|l|}{ BMI, n (\%) } \\
\hline Normal & $553(27.2)$ & $88(14.1)$ & $465(33.0)$ \\
\hline Underweight & $11(0.5)$ & $3(0.5)$ & $8(0.6)$ \\
\hline Overweight & $521(25.7)$ & $144(23.2)$ & $377(26.8)$ \\
\hline Apparently overweight & 464 (22.9) & $183(29.4)$ & $281(20.0)$ \\
\hline Obesity & $481(23.7)$ & $204(32.8)$ & $277(19.7)$ \\
\hline
\end{tabular}

Continued

\section{Female}

$2433(60.0)$

$1408(57.9)$

$56.19(49,63)$

1135 (80.6)

273 (19.4)

1290 (91.6)

$33.27(32,35)$

$97.76(93,102)$

$5.63(4.87,6.29)$

$2.19(1.57,2.65)$

1079 (76.6)

995 (70.7)

$590(41.9)$

$1252(88.9)$

601 (96.6)

$630(44.7)$

$549(39)$

149 (10.6)

$80(5.7)$

$\begin{array}{lrr}253(12.5) & 104(16.7) & 149(10.6) \\ 142(7.0) & 62(10.0) & 80(5.7)\end{array}$

$1023(50.4)$

$357(57.4)$

$666(47.3)$

$742(52.7)$

$798(56.7)$

$610(43.3)$

Physical inactivity, n (\%) 


\section{Table 1 Continued}

Values are expressed as $n$ (percentage).

BMI, body mass index; FBG, fasting blood glucose; HDL-C, high-density lipoprotein; LDL-C, low-density lipoprotein cholesterol; TCHO, total serum cholesterol; TG, triglyceride.

MS, whereas physical inactivity and fruit consumption were not. For men, the risk factors associated with MS were similar, except for age, smoking and higher alcohol consumption. Unlike in women, physical inactivity and light/moderate alcohol consumption were also risk factors in men.

\section{Relationship between risk factors and MS in the multivariable logistic regression analysis}

Multivariable analysis revealed that BMI and hip circumference were significantly associated with MS in both men and women (table 3). Age, region and educational attainment were associated with MS in women, while physical inactivity was associated with MS in men. Neck circumference, an underweight BMI, smoking, and alcohol consumption were not associated with MS in either sex.

For men, BMI, hip circumference and physical inactivity were associated with MS. The ORs (95\% CIs) were 2.07 (1.48 to 2.90; $\mathrm{p}<0.001$ ) for overweight BMI, 3.77 (2.54 to 5.60; $\mathrm{p}<0.001$ ) for apparently overweight BMI, and 3.25 (2.02 to 5.24; $\mathrm{p}<0.001$ ) for obese BMI. For hip circumference, the OR $(95 \% \mathrm{CI})$ was 1.12 (1.09 to 1.15 ; $\mathrm{p}<0.001)$. Physical inactivity was associated with MS in men (OR $1.44,95 \%$ CI (1.06 to 1.97$), \mathrm{p}=0.022$ ).

Table 2 Univariable logistic regression analyses on risk factors for the prevalence of metabolic syndrome in men and women

\begin{tabular}{|c|c|c|c|c|c|}
\hline & & Male & & Female & \\
\hline Category & Reference & OR $(95 \% \mathrm{Cl})$ & $P$ value & OR $(95 \% \mathrm{Cl})$ & $P$ value \\
\hline Age group & 40-64 years & & & & \\
\hline$\geq 65$ years & & 1.10 (0.85 to 1.42$)$ & 0.482 & 2.04 (1.61 to 2.59$)$ & $<0.001$ \\
\hline HP & - & 1.20 (1.18 to 1.22$)$ & $<0.001$ & 1.16 (1.14 to 1.17$)$ & $<0.001$ \\
\hline NC & - & 1.44 (1.38 to 1.51$)$ & $<0.001$ & 1.37 (1.31 to 1.42$)$ & $<0.001$ \\
\hline Region & Urban & & & & \\
\hline Rural & & $0.57(0.46$ to 0.69$)$ & $<0.001$ & 1.66 (1.41 to 1.95$)$ & $<0.001$ \\
\hline Smoke & No & & & & \\
\hline Yes & & $0.93(0.75$ to 1.14$)$ & 0.472 & 1.41 (1.19 to 1.66$)$ & $<0.001$ \\
\hline Physical inactivity & Physical activity & & & & \\
\hline Yes & & 1.75 (1.36 to 2.24$)$ & $<0.001$ & 1.12 (0.93 to 1.35$)$ & 0.235 \\
\hline Alcohol consumption & Never & & & & \\
\hline Light/moderate drinking & & 1.44 (1.12 to 1.84$)$ & 0.004 & 0.50 (0.16 to 1.59$)$ & 0.243 \\
\hline Higher drinking & & $0.99(0.78$ to 1.26$)$ & 0.949 & $0.61(0.43$ to 0.86$)$ & 0.005 \\
\hline Fruit consumption & $\geq 5$ days/week & & & & \\
\hline 3-4 days per week & & 1.09 (0.77 to 1.53$)$ & 0.627 & 1.19 (0.89 to 1.60$)$ & 0.238 \\
\hline$\leq 2$ days per week & & 0.80 (0.43 to 1.51$)$ & 0.494 & 1.37 (0.83 to 2.26$)$ & 0.226 \\
\hline Education & $\leq$ Primary school & & & & \\
\hline Junior middle school & & 1.28 (1.01 to 1.62$)$ & 0.040 & 0.59 (0.49 to 0.71$)$ & $<0.001$ \\
\hline Senior middle school & & 1.75 (1.27 to 2.41$)$ & 0.001 & 0.41 (0.32 to 0.54$)$ & $<0.001$ \\
\hline College and above & & 1.31 (0.91 to 1.90$)$ & 0.149 & 0.27 (0.20 to 0.37$)$ & $<0.001$ \\
\hline BMI & Normal & & & & \\
\hline Underweight & & 1.49 (0.42 to 5.33$)$ & 0.540 & 0.30 (0.14 to 0.66$)$ & 0.002 \\
\hline Overweight & & 3.91 (2.88 to 5.30$)$ & $<0.001$ & 3.54 (2.85 to 4.40$)$ & $<0.001$ \\
\hline Apparently overweight & & 11.14 (8.03 to 15.47$)$ & $<0.001$ & 5.28 (4.01 to 6.93$)$ & $<0.001$ \\
\hline Obesity & & 18.29 (12.89 to 25.96$)$ & $<0.001$ & 12.03 (8.31 to 17.43 ) & $<0.001$ \\
\hline
\end{tabular}

Values are expressed as median (IQR) or $\mathrm{n}$ (percentage).

$\mathrm{BMI}$, body mass index; HC, hip circumference; NC, neck circumference. 


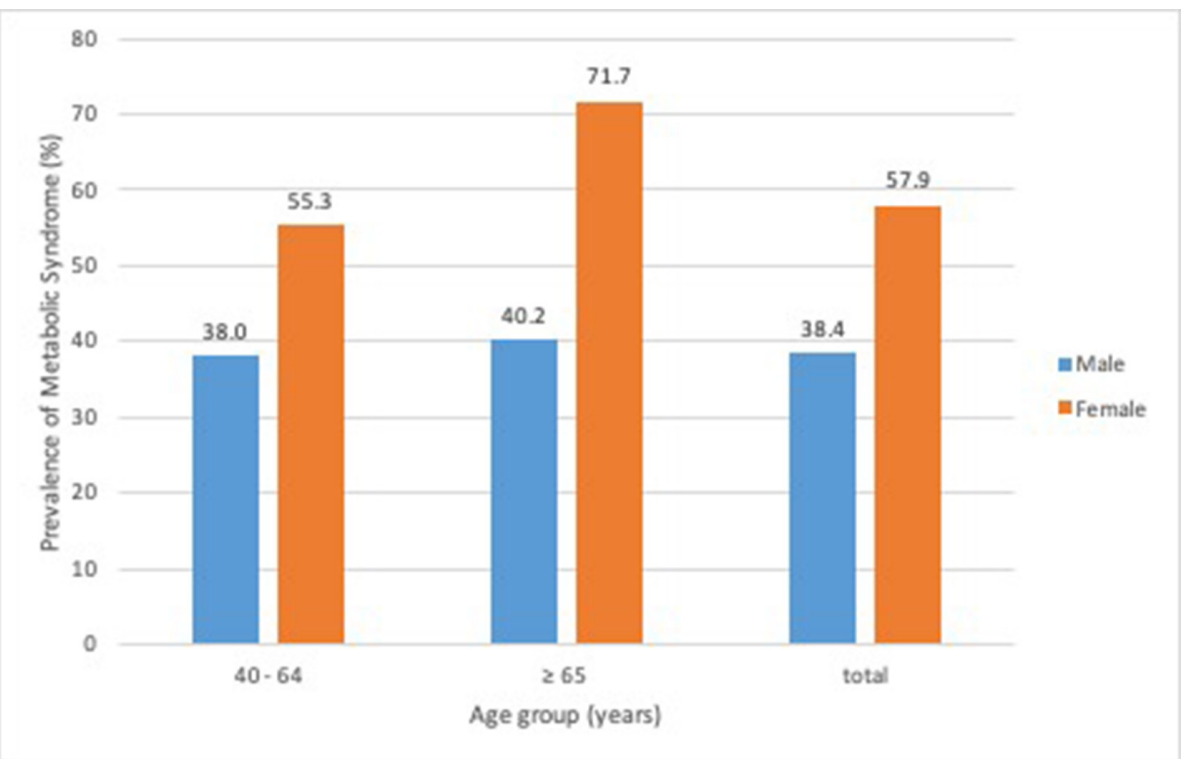

Figure 2 Prevalence of metabolic syndrome in different sexes and ages in the study.

Table 3 Multivariable logistic regression analyses on risk factors for the prevalence of metabolic syndrome in men and women.

\begin{tabular}{|c|c|c|c|c|c|}
\hline & & Male & & Female & \\
\hline Category & Reference & OR $(95 \% \mathrm{Cl})$ & $P$ value & OR $(95 \% \mathrm{Cl})$ & $P$ value \\
\hline Age group & $40-64$ yea & & & & \\
\hline$\geq 65$ years & & - & - & 1.54 (1.15 to 2.04$)$ & 0.003 \\
\hline Education & $\leq$ Primary & & & & \\
\hline Junior middle school & & 0.92 (0.66 to 1.27$)$ & 0.606 & 0.62 (0.48 to 0.79$)$ & $<0.001$ \\
\hline Senior middle school & & 1.01 (0.64 to 1.61$)$ & 0.953 & 0.58 ( 0.40 to 0.83 ) & 0.003 \\
\hline College and above & & 0.73 (0.43 to 1.23$)$ & 0.231 & 0.43 (0.29 to 0.66$)$ & $<0.001$ \\
\hline Region & Urban & & & & \\
\hline Rural & & 0.82 (0.59 to 1.13$)$ & 0.223 & 0.74 (0.56 to 0.97$)$ & 0.028 \\
\hline BMI & Normal & & & & \\
\hline Underweight & & 2.46 (0.58 to 10.50$)$ & 0.223 & 0.57 (0.25 to 1.30$)$ & 0.183 \\
\hline Overweight & & 2.07 (1.48 to 2.90$)$ & $<0.001$ & 2.09 (1.63 to 2.68 ) & $<0.001$ \\
\hline Apparently overweight & & 3.77 (2.54 to 5.60$)$ & $<0.001$ & 2.01 (1.46 to 2.79 ) & $<0.001$ \\
\hline Obesity & & 3.25 (2.02 to 5.24$)$ & $<0.001$ & 2.55 (1.62 to 4.00$)$ & $<0.001$ \\
\hline Neck circumference & - & 1.19 (0.95 to 1.50$)$ & 0.128 & 1.19 (0.95 to 1.50$)$ & 0.128 \\
\hline Smoke & No & & & & \\
\hline Yes & & - & - & 1.19 (0.95 to 1.50$)$ & 0.128 \\
\hline Physical inactivity & Physical a & & & & \\
\hline Yes & & 1.44 (1.06 to 1.97$)$ & 0.022 & - & - \\
\hline Alcohol consumption & Never & & & & \\
\hline Light/moderate drinking & & 0.88 (0.66 to 1.18$)$ & 0.400 & 0.72 (0.48 to 1.08 ) & 0.112 \\
\hline Higher drinking & & 1.32 (0.98 to 1.78$)$ & 0.07 & $0.43(0.11$ to 1.63$)$ & 0.215 \\
\hline Hip circumference & & $1.12(1.09$ to 1.15$)$ & $<0.001$ & 1.10 (1.08 to 1.12$)$ & $<0.001$ \\
\hline
\end{tabular}

BMI, body mass index.; 
For women, BMI, hip circumference and advanced age were associated with MS. Rural residence and junior middle-school education or above were negatively associated with MS. The higher the education attainment, the lower the risk of MS. The ORs (95\% CIs) were 2.09 (1.63 to 2.68; $\mathrm{p}<0.001)$ for overweight BMI, 2.01 (1.46 to $2.79 ; \mathrm{p}<0.001)$ for apparently overweight BMI, and 2.55 (1.62, 4.00; $\mathrm{p}<0.001$ ) for obese BMI groups. For hip circumference, the OR $(95 \% \mathrm{CI})$ was 1.10 (1.08 to 1.12; $\mathrm{p}<0.001)$. The OR $(95 \% \mathrm{CI})$ for advanced age ( $\geq 65$ years) was 1.54 ( 1.15 to 2.04 ); $\mathrm{p}=0.003$ ). The OR (95\% CI) for living in a rural region was 0.74 (0.56 to $0.97 ; \mathrm{p}=0.028$ ). For an educational level of junior middle-school, the OR (95\% CI) was 0.62 ( 0.48 to $0.79 ; \mathrm{p}<0.001)$; for senior middle-school, it was 0.58 ( 0.40 to 0.83 ; $\mathrm{p}=0.003)$, and for college and above, it was 0.43 ( 0.29 to 0.66 ; $\mathrm{p}<0.001)$.

\section{DISCUSSION}

In this study, we evaluated sex-based differences in the prevalence of MS and its relative determinants in a lowincome population from Northeast China. We found that in addition to being significantly more prevalent in women than in men, a high BMI, and large hip circumference were risk factors for MS in both sexes. In addition, advanced age ( $\geq 65$ years) was a risk factor only for women, whereas physical inactivity was a risk factor only for men. Furthermore, educational attainment and living in a rural region were negatively associated with MS in women, but not in men.

The prevalence of MS has been steadily increasing due to unhealthy lifestyles in low-income and high-income regions, ${ }^{10} 11$ and there are known sex differences.

The prevalence of MS in those living in the Chinese mainland for both the low-income, middle-income and high-income populations was shown to be $33.9 \%$ in $2010^{1}$; however, in our study, it was $50.1 \%$. This may be because most of the participants in our study population had a lower educational level and income, which may have had an additive effect on the primary, increasing trend. In most studies, the prevalence of MS in women was higher than that in men ${ }^{112}$; for example, in Mexico, the prevalence in women was $55.6 \%$, whereas in men, it was $38.2 \% .^{13}$ Similar sex disparities were observed in Middle Eastern countries, but few sex differences have been reported in the European Union, which has a lower MS prevalence overall. ${ }^{14}$ In contrast, the prevalence of MS in men is higher than that in women in Caucasians, ${ }^{15}$ American adolescents, ${ }^{16}$ Far East Asian and Japanese populations, and in Macau, it is twice that in women. ${ }^{17}$ These differences may be related to race, the period in which the studies were conducted, the geographic region and the selection criteria used. ${ }^{18-20}$ Our results were consistent with those reported in most countries that women had a higher prevalence of MS than men. ${ }^{21-24}$ In addition, these sex-related differences were shown to be greater in women of advanced age, but remained relatively stable with respect to age in men in East China. ${ }^{25}$ This was consistent with our own findings that women aged $\geq 65$ years had a 1.536 -fold higher risk of MS than those aged 40-65 years. A decrease in oestrogen levels in women after menopause results in an increase in insulin resistance and abnormal lipid metabolism. Thus, the sex differences observed may be related to changes in hormone levels, rather than ageing itself. ${ }^{26}$

It is well known that MS prevalence increases when BMI $\left(\geq 24 \mathrm{~kg} / \mathrm{m}^{2}\right)$ is higher than normal. Compared with individuals with a normal BMI, the risk of MS with an overweight and obese BMI was 3.11-fold and 17.18-fold in Korean women, and 4.30-fold and 10.91-fold in Korean men without diabetes mellitus, respectively. ${ }^{27}$ Our study also found that compared with a normal BMI, a higher BMI was associated with higher odds of MS. The risk was 2.09-fold, 2.01-fold and 2.55-fold higher in overweight, significantly overweight and obese females, respectively. In men, the risk increased 2.07-fold, 3.77-fold and 3.25fold, respectively. These findings also suggest that weight gain in men (BMI $\geq 26 \mathrm{~kg} / \mathrm{m}^{2}$ ) increases the risk of MS more substantially than it does in women; this positive association has also been reported in a study of Turkish adults. ${ }^{28}$ An Israeli cohort study claimed that a normal BMI had a high negative predictive value in both men $(98 \%)$ and women $(96 \%)$ with respect to $\mathrm{MS}^{29}$ The inverse association was found between hip circumference and metabolic risk factors in Tehranian women. ${ }^{30}$ Further, weak predictive ability was found for hip circumference. In our study, the risk of MS increased 1.10-fold in women and 1.12-fold in men for every $1 \mathrm{~cm}$ increase in hip circumference but not in neck circumference. Thus, BMI combined with hip circumference is an effective indicator of being overweight or obese, and such individuals are more prone to developing MS. Whether obesity or insulin resistance is a cause or consequence of MS is still under debate. ${ }^{31}$ Adipokines produced by abnormal adipocytes cause insulin resistance, and visceral obesity may be a causal factor of metabolic disease. ${ }^{32}$

Physical inactivity was a main risk factor for men in our study, consistent with the findings of a previous study. ${ }^{33}$ Infrequent physical activity results in a 1.44-fold increased risk of MS in men, but not in women, this is consistent with previous findings. ${ }^{34}$ Moreover, physical activity has been suggested to be associated with a low risk for MS. ${ }^{35}$ Studies have also found that binge drinking and smoking were associated with increased MS prevalence, regardless of sex or BMI. ${ }^{3637}$ The association between fruit consumption, neck circumference and MS risk remains unclear; in our study, no significant associations were observed among alcohol consumption, smoking, fruit consumption or neck circumference.

Educational level is the most important measure of socioeconomic status, which has been shown to not only affect the prevalence of MS, but is also closely related to the prevalence of cerebrovascular disease. ${ }^{38}$ The specific mechanism by which education affects the prevalence of MS is unclear. It has, however, been considered that education influences people's lifestyles and positive attitudes toward health, and increases their access to 
preventive health services. ${ }^{39}$ In addition, it is reported in South Korea, that the negative correlation between educational level and MS prevalence is largely related to the dietary patterns of Koreans (especially in women).$^{40}$ For women in our study, the ORs indicated a 0.62-fold, 0.58fold and 0.43-fold risk of developing MS in those who had completed junior middle school, senior middle school, as well as college and above, respectively. This suggests that a higher educational level can reduce the risk of MS; however, this relationship was not found in men. The negative association between MS prevalence and educational level was significant in women, which is similar to the results of a previous study. ${ }^{40}$ A National Survey found that low income and educational levels were associated with a higher prevalence of MS in women than in men. ${ }^{41}$ Our study population was characterised by having both a low income and a low level of education, both of which contributed to a higher MS prevalence. The percentage of included women with a primary school education or below was $37.8 \%$, which may partially explain the high prevalence of MS in women. ${ }^{24}$ Urban adults $(\geq 18$ years old) in China were more likely than rural adults to have MS in 2009, ${ }^{22}$ The opposite was true among urban adults in Jiangxi province, China in 2015, as women living in rural areas were more likely than urban females to have MS. These findings were not observed among men. ${ }^{42}$ In our study, MS was negatively associated with living in rural regions (OR: 0.74 (0.56 to 0.97 ), $\mathrm{p}=0.028$ ) but not with living in urban regions. The differences may be caused by the degree of economic development, lifestyle habits and dietary patterns; for example, rural women have lower fat intake and more activity than urban women. ${ }^{43}$

Lifestyle interventions resulted in a 2.61-fold reduced risk of MS compared with the control group in a previous study. ${ }^{44}$ An investigation of dietary patterns showed that the Chinese pattern (high in grains, vegetables, fruit, salted fish and eggs, soyabean, etc) was associated with a lower risk of MS than the animal food pattern (high in meats, fish and shrimp, eggs, seafood, alcoholic beverages, etc.). ${ }^{45}$ Sex differences in the dietary patterns were associated with increased MS prevalence; for example, an increased prevalence was observed in men consuming an 'animal and fried food' diet, and women consuming a 'high-salt and energy' diet. ${ }^{19}$ Muscle strength and cardiorespiratory fitness may independently and jointly reduce the incidence of $\mathrm{MS}^{46}$ as increased physical activity decreased the risk by $19 \%-24 \% .{ }^{47}$ In men, every hour of exercise may decrease MS risk by $2 \%{ }^{48}$ In contrast, daily sedentary behaviour linearly increases the risk of MS by 1.09 times per hour. ${ }^{49}$ To prevent the onset of MS, a better understanding of modifiable lifestyle factors is needed in high-risk populations; for example, in men who are physically inactive, further effort should be made to control body weight, especially by focusing on reducing high BMI and hip circumference. Moreover, exercise can result in high brain insulin sensitivity, which can help to lose more body weight and body fat with a lower regain. ${ }^{50}$ For women, especially the elderly outside rural regions, efforts should be made to control weight to maintain BMI and hip circumference at normal levels to reduce the risk of MS. Focus should also be directed at changes in hormone levels, especially the low concentrations of sex hormone-binding globulin and testosterones, which increase the odds of MS. ${ }^{51}$ In the long run, a higher level of educational attainment can reduce the risk of MS. Understanding these factors and the sex differences between them, as well as accurately identifying high-risk groups, could help to develop better public health policies, educational initiatives and reduce the incidence of MS and vascular diseases. There were also several limitations to this study. Some data were self-reported, each parameter in blood was only sampled and measured once, and some lifestyle factors and potential residual confounders were not assessed. Furthermore, people who were sick or too weak to participate were excluded, which may impact the generalisability of the results. Moreover, cross-sectional studies cannot be used to make causal inferences, and subsequent prospective and randomised studies are needed.

\section{CONCLUSION}

In our study, we found that risk factors for MS have both sex-based similarities and differences; thus, the prevention and treatment of MS should consider patients' sex.

\section{Author affiliations}

${ }^{1}$ Stroke Center, Department of Neurology, The First Hospital of Jilin University, Changchun, Jilin, China

${ }^{2}$ Stroke Center, Department of Neurology, The Affiliated Hospital of Beihua University, JiLin, Jilin, China

${ }^{3}$ Clinical Trial and Research Center for Stroke, Department of Neurology, The First Hospital of Jilin University, Changchun, Jilin, China

Acknowledgements The authors gratefully acknowledge all of the study participants and interviewers from the First Hospital of Jilin University, and acknowledge the support of the Chinese National Centre for Stroke Care Quality Control and Management. We would like to thank Editage (www.editage.cn) for English language editing.

Contributors Conception and design: YY and Z-N G. Acquisition of the data: F-L Z and H-Y L. Statistical methods and data analysis: F-E L, PZ, DL and F-L Z. Drafting and revising the manuscript: F-E L. Critical revision: Z-N G and YY. All authors approved the final version for publication.

Funding This project was supported by the National Key R\&D Program of China (2016YFC1301600), JLUSTIRT (2017TD-12) and Jilin Provincial Key Laboratory (20190901005JC) to Yi Yang. Project on research and application of effective intervention techniques for high risk population of stroke from the National Health and Family Planning Commission in China (GN-2016R0010).

Competing interests None declared.

Patient consent for publication Obtained.

Ethics approval This subject was approved by the human ethics and research ethics committee of the First Hospital of Jilin University (approval No: 2015-R-250 R-250), and written informed consent was obtained from all of the participants.

Provenance and peer review Not commissioned; externally peer reviewed.

Data availability statement Data are available upon reasonable request by email.

Supplemental material This content has been supplied by the author(s). It has not been vetted by BMJ Publishing Group Limited (BMJ) and may not have been peer-reviewed. Any opinions or recommendations discussed are solely those of the author(s) and are not endorsed by BMJ. BMJ disclaims all liability and 
responsibility arising from any reliance placed on the content. Where the content includes any translated material, BMJ does not warrant the accuracy and reliability of the translations (including but not limited to local regulations, clinical guidelines, terminology, drug names and drug dosages), and is not responsible for any error and/or omissions arising from translation and adaptation or otherwise.

Open access This is an open access article distributed in accordance with the Creative Commons Attribution Non Commercial (CC BY-NC 4.0) license, which permits others to distribute, remix, adapt, build upon this work non-commercially, and license their derivative works on different terms, provided the original work is properly cited, appropriate credit is given, any changes made indicated, and the use is non-commercial. See: http://creativecommons.org/licenses/by-nc/4.0/.

ORCID iD

Yi Yang http://orcid.org/0000-0002-9729-8522

\section{REFERENCES}

1 Lu J, Wang L, Li M, et al. Metabolic syndrome among adults in China: the 2010 China noncommunicable disease surveillance. J Clin Endocrinol Metab 2017;102:507-15.

2 Kokubo Y, Matsumoto C. Hypertension is a risk factor for several types of heart disease: review of prospective studies. Adv Exp Med Biol 2017;956:419-26.

3 Isomaa B, Almgren P, Tuomi T, et al. Cardiovascular morbidity and mortality associated with the metabolic syndrome. Diabetes Care 2001;24:683-9.

4 Aguilar M, Bhuket T, Torres S, et al. Prevalence of the metabolic syndrome in the United States, 2003-2012. JAMA 2015;313:1973-4.

5 Song Q-B, Zhao Y, Liu Y-Q, et al. Sex difference in the prevalence of metabolic syndrome and cardiovascular-related risk factors in urban adults from 33 communities of China: the CHPSNE study. Diab Vasc Dis Res 2015;12:189-98.

6 Wang W, Jiang B, Sun H, et al. Prevalence, Incidence, and Mortality of Stroke in China: Results from a Nationwide Population-Based Survey of 480687 Adults. Circulation 2017;135:759-71.

7 Sun H, Zou X, Liu L. Epidemiological factors of stroke: a survey of the current status in China. J Stroke 2013;15:109-14.

8 Zhang F-L, Guo Z-N, Wu Y-H, et al. Prevalence of stroke and associated risk factors: a population based cross sectional study from Northeast China. BMJ Open 2017;7:e015758.

9 Alberti KGMM, Eckel RH, Grundy SM, et al. Harmonizing the metabolic syndrome: a joint interim statement of the Internationa diabetes Federation Task force on epidemiology and prevention; National heart, lung, and blood Institute; American heart association; world heart Federation; international atherosclerosis Society; and international association for the study of obesity. Circulation 2009;120:1640-5.

10 Suliga E, Kozieł D, Ciesla E, et al. Consumption of alcoholic beverages and the prevalence of metabolic syndrome and its components. Nutrients 2019;11:2764.

11 Ansarimoghaddam A, Adineh HA, Zareban I, et al. Prevalence of metabolic syndrome in Middle-East countries: meta-analysis of cross-sectional studies. Diabetes Metab Syndr 2018;12:195-201.

12 Rochlani Y, Pothineni NV, Mehta JL. Metabolic syndrome: does it differ between women and men? Cardiovasc Drugs Ther 2015;29:329-38.

13 Mendoza-Caamal EC, Barajas-Olmos F, García-Ortiz H, et al. Metabolic syndrome in Indigenous communities in Mexico: a descriptive and cross-sectional study. BMC Public Health 2020:20:339.

14 Patel A, Huang K-C, Janus ED, et al. Is a single definition of the metabolic syndrome appropriate?--A comparative study of the USA and Asia. Atherosclerosis 2006;184:225-32.

15 Firmann M, Mayor V, Vidal PM, et al. The CoLaus study: a population-based study to investigate the epidemiology and genetic determinants of cardiovascular risk factors and metabolic syndrome. BMC Cardiovasc Disord 2008;8:6.

16 Miller JM, Kaylor MB, Johannsson M, et al. Prevalence of metabolic syndrome and individual criterion in US adolescents: 2001-2010 National health and nutrition examination survey. Metab Syndr Relat Disord 2014;12:527-32.

17 Ishii S, Tanaka T, Akishita M, et al. Metabolic syndrome, sarcopenia and role of sex and age: cross-sectional analysis of Kashiwa cohort study. PLoS One 2014;9:e112718.

18 Mozumdar A, Liguori G. Persistent increase of prevalence of metabolic syndrome among U.S. adults: NHANES III to NHANES 1999-2006. Diabetes Care 2011;34:216-9.
19 Mabry RM, Reeves MM, Eakin EG, et al. Gender differences in prevalence of the metabolic syndrome in Gulf cooperation Council countries: a systematic review. Diabet Med 2010;27:593-7.

20 Erem C, Hacihasanoglu A, Deger O, et al. Prevalence of metabolic syndrome and associated risk factors among Turkish adults: Trabzon Mets study. Endocrine 2008;33:9-20.

21 Yu S, Guo X, Yang H, et al. An update on the prevalence of metabolic syndrome and its associated factors in rural northeast China. BMC Public Health 2014;14:877.

$22 \mathrm{Xi} \mathrm{B}, \mathrm{He} \mathrm{D,} \mathrm{Hu} \mathrm{Y,} \mathrm{et} \mathrm{al.} \mathrm{Prevalence} \mathrm{of} \mathrm{metabolic} \mathrm{syndrome} \mathrm{and} \mathrm{its}$ influencing factors among the Chinese adults: the China health and nutrition survey in 2009. Prev Med 2013;57:867-71.

23 Jiang B, Li B, Wang Y, et al. The nine-year changes of the incidence and characteristics of metabolic syndrome in China: longitudinal comparisons of the two cross-sectional surveys in a newly formed urban community. Cardiovasc Diabetol 2016;15:84.

24 Wu LT, Shen YF, Hu L, et al. Prevalence and associated factors of metabolic syndrome in adults: a population-based epidemiological survey in Jiangxi Province, China. BMC Public Health 2020;20:133.

25 Jiang B, Zheng Y, Chen Y, et al. Age and gender-specific distribution of metabolic syndrome components in East China: role of hypertriglyceridemia in the SPECT-China study. Lipids Health Dis 2018;17:92.

26 Janssen I, Powell LH, Crawford S, et al. Menopause and the metabolic syndrome: the study of women's health across the nation. Arch Intern Med 2008;168:1568-75.

27 Lee K, Lee H, Park J, et al. Sex differences in factors associated with metabolic syndrome among Korean adults without diabetes mellitus: results from the Korea National health and nutrition examination survey from 2010 to 2013. Fam Pract 2019;36:140-6.

28 Gundogan K, Bayram F, Gedik V, et al. Metabolic syndrome prevalence according to ATP III and IDF criteria and related factors in Turkish adults. Arch Med Sci 2013;9:243-53.

29 Kobo O, Leiba R, Avizohar O, et al. Normal body mass index (BMI) can rule out metabolic syndrome: an Israeli cohort study. Medicine 2019;98:e14712.

30 Esmaillzadeh A, Mirmiran P, Moeini SH, et al. Larger hip circumference independently contributed to reduced metabolic risks in Tehranian adult women. Int J Cardiol 2006;108:338-45.

$31 \mathrm{Xu} \mathrm{H}$, Li X, Adams H, et al. Etiology of metabolic syndrome and dietary intervention. Int J Mol Sci 2018;20:128.

32 Svensson H, Odén B, Edén S, et al. Adiponectin, chemerin, cytokines, and dipeptidyl peptidase 4 are released from human adipose tissue in a depot-dependent manner: an in vitro system including human serum albumin. BMC Endocr Disord 2014;14:7.

33 Zhou J-ya, Ge H, Zhu M-fan, et al. Neck circumference as an independent predictive contributor to cardio-metabolic syndrome. Cardiovasc Diabetol 2013;12:76.

34 Díaz-Martínez X, Petermann F, Leiva AM, et al. [Association of physical inactivity with obesity, diabetes, hypertension and metabolic syndrome in the chilean population]. Rev Med Chil 2018;146:585-95.

35 Liu Y, Huang J, Xu G, et al. Prevalence and determinants of metabolic Syndrome-identified by three criteria among men in rural China: a population-based cross-sectional study conducted during 2007-2008. J Nutr Health Aging 2016;20:574-82

36 Oh JE. Relationship between heavy drinking, binge drinking, and metabolic syndrome in obese and non-obese Korean male adults. Nutr Res Pract 2018;12:166-72.

37 Slagter SN, van Vliet-Ostaptchouk JV, Vonk JM, et al. Associations between smoking, components of metabolic syndrome and lipoprotein particle size. BMC Med 2013;11:195.

38 Seo SR, Kim SY, Lee S-Y, et al. The incidence of stroke by socioeconomic status, age, sex, and stroke subtype: a nationwide study in Korea. J Prev Med Public Health 2014;47:104-12.

39 Winkleby MA, Jatulis DE, Frank E, et al. Socioeconomic status and health: how education, income, and occupation contribute to risk factors for cardiovascular disease. Am J Public Health 1992;82:816-20.

40 Kim OY, Kwak S-Y, Kim B, et al. Selected food consumption mediates the association between education level and metabolic syndrome in Korean adults. Ann Nutr Metab 2017;70:122-31.

41 Loucks EB, Rehkopf DH, Thurston RC, et al. Socioeconomic disparities in metabolic syndrome differ by gender: evidence from NHANES III. Ann Epidemiol 2007;17:19-26.

42 Wu LT, Shen YF, Hu L. Prevalence and associated factors of metabolic syndrome in adults: a population-based epidemiological survey in Jiangxi Province, China. BMC Public Health 2020;20:133.

43 Chung S-J, Han YS, Lee S-I, et al. Urban and rural differences in the prevalence of gender and age specific obesity and related health behaviors in Korea. J Korean Med Sci 2005;20:713-20. 
44 Guzmán A, Navarro E, Obando L, et al. Effectiveness of interventions for the reversal of a metabolic syndrome diagnosis: an update of a meta-analysis of mixed treatment comparison studies. Biomedica 2019;39:647-62.

45 Wei Z-Y, Liu J-J, Zhan X-M, et al. Dietary patterns and the risk of metabolic syndrome in Chinese adults: a population-based crosssectional study. Public Health Nutr 2018;21:2409-16.

46 Jurca R, Lamonte MJ, Barlow CE, et al. Association of muscular strength with incidence of metabolic syndrome in men. 2005;37:1849-55.

47 Xiao J, Wu C-L, Gao Y-X, et al. Prevalence of metabolic syndrome and its risk factors among rural adults in Nantong, China. Sci Rep 2016;6:38089.
48 Renninger M, Hansen BH, Steene-Johannessen J, et al. Associations between accelerometry measured physical activity and sedentary time and the metabolic syndrome: a meta-analysis of more than 6000 children and adolescents. Pediatr Obes 2020;15:e12578.

49 Gennuso KP, Gangnon RE, Thraen-Borowski KM, et al. Doseresponse relationships between sedentary behaviour and the metabolic syndrome and its components. Diabetologia 2015;58:485-92.

50 Kullmann S, Valenta V, Wagner R, et al. Brain insulin sensitivity is linked to adiposity and body fat distribution. Nat Commun 2020;11:1841.

$51 \mathrm{Li} \mathrm{C}$, Ford ES, Li B, et al. Association of testosterone and sex hormone-binding globulin with metabolic syndrome and insulin resistance in men. Diabetes Care 2010;33:1618-24. 